\title{
The Influence Relationship Between Climate Change and Economic Growth: Linear and Nonlinear Granger Causality Analysis for Nigeria
}

\author{
Dahiru Alhaji Bala Birnintsaba \& Ahmad Sulaiman \\ Department of Banking and Finance \\ Federal Polytechnic Kaura Namoda \\ Zamfara State, Nigeria \\ E-mail: dahirubala5002@gmail.com
}

\begin{abstract}
Recently examining the role of climate change in economic growth has gained considerable attention among scholars. In doing so, they usually employed $\mathrm{CO} 2$ emission or the temperature level as proxies of climate change. With this in mind, we empirically revisit the linear and nonlinear causal relationships amid climate change and economic growth using both of these indexes for Nigeria. For the nonlinear consideration, in addition, application of granger test for linear and nonlinear causality, we also benefit from bias-free methodology of nonparametric test using Granger causality. The standard causal linear tests do not discover any causative flows between the series under examination. Yet, we show that among the variables there exist nonlinear processes. Hence, these results are not well grounded due to the inability of the direct causality test to capture the inventive phenomena in the data. However, according to Granger causality test a nonlinear unidirectional evidence of causality that affect the economic growth to $\mathrm{CO} 2$ emissions was found to be unidirectional while for a temperature - growth nexus a bidirectional causal link was detected.
\end{abstract}

Keywords: Economic Growth, CO2 Emissions, Climate Change, Nonlinear Granger, Nigeria, JEL Codes: 011, Q54, C54

\section{INTRODUCTION}

Change in climate can be viewed as a focal point for the world's economic difficulties. Evaluation of the economic consequences brought by change in climate is multifaceted in nature. The arrangement of systems through which climate may impact economic results, directly or indirectly, is to a great degree substantial and hard to examine exhaustively. It is important to examine how different climate factors combine to impact macroeconomic results. Due to the general consensus that greenhouse gas emissions are warming the world's climate, studies have progressively centered on evaluating the effects that are likely to occur. 


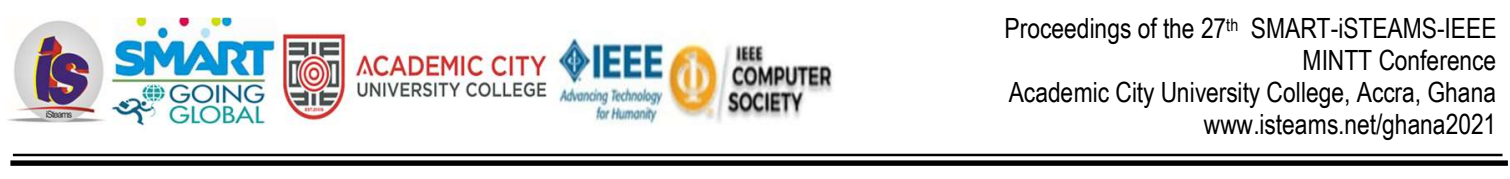

Scholars such as Nwafor, 2007; Beyioku J, 2016; Awais M. et al, 2018 explained climate change as a series of problems resulting from adverse weather conditions, environmental pollution, insecurity, flooding and economic hardship. They demonstrated that although climate change will be experienced around the world, the real impacts will greatly affect developing countries, particularly the Africa nations, because of their inability to adjust (Nwafor 2007 and Jagtap 2007). In another study, Beyioku J. (2016) observed that change in climate is largely caused by the rapid development of human ventures on the earth, which affects wellbeing as well as long-term negative impacts resulting in the world continuing to be at risk due to climate change issues. (Wade K. and Jennings M, 2015; McMichael A et al, 2015) classified African and Asian countries with a higher vulnerability of climate change, for instance, Nigeria, with a higher level of temperature and climate conditions, moves significantly from $12{ }^{\circ} \mathrm{C}$ to $38{ }^{\circ} \mathrm{C}$ as a result of seasonal rainfall, which varies between $50 \mathrm{CM}$ and $430 \mathrm{CM}$. This concurs with (Ruth 2017), who recognized that impacts of change in climate on Nigeria emerged from different climate change-related causes.

The subject of climate change has enticed significant amount of thought in the arena of learning, which signifies the need to investigate the effect of environmental factors on economic productivity. Any investigations of change in climate must incorporate a model that interprets changes in climate-related factors and its relation with economic indicators. In view of this, the study attempts to detect the novel directions among economic growth and climate change through temperature and $\mathrm{CO} 2$ emissions in Nigeria. Nigeria is a country that has significant potential through crops and fuel-wood, bio-gas, wind, solar and hydro energy, although they are being underused. As in a significant number of advanced nations with similar resources that are focused on renewable energy, executing any course of action that will incite reasonable and sustainable energy improvement as a backbone of climate control and economic development is crucial. Researchers have demonstrated that Nigeria is now suffering from a variety of issues in nature that are unequivocally linked with ongoing problem of change in climate, (NEST 2003; Ayuba et al., 2007, Akpodiogaga and Odjugo, 0. 2010).

Most of the studies in the literature reviewed focus on explaining the concepts of change in climate and the method of conformity and mitigation, in a latest research development many scholars accented the impact of abject $\mathrm{Co} 2$ relatives to different disciplines such as production and industries, socio-economic and education industry; see (Wang S. et al, 2018; Wu, 2017; Liu et al, 2016) while there are few studies on the impact on economic growth. Sulaiman C. et el. (2014) in their study on Nigeria, detected that economic productivity has a significant and direct influence to $\mathrm{CO} 2$ emissions within short period and long-run using autoregressive distributed lag approach and environmental Kuznets curve. (Saboori et al, 2017; Choi et al, 2010) studied the connections between CO2 and growth testing panel data of China, Japan and Korea annually 19712006. Their findings show that the variables have a varied influence amongst the countries studied. Their results are consistent with research conducted by (Moomaw and Unruh, 1997; Fried and Getzner, 2003) studied the connections between GDP and CO2 in advanced economies. Frankhauser and Tol (2005) conducted hypothetical investigations on change in climate and economic growth utilizing a straightforward atmospheric condition and economic competitive perspective. They reasoned that, as time goes on, in terms of high positive shocks, changes in the climate may unquestionably pivot budgetary development and per capita income may fall. Likewise, Abidoye and Odusola (2015) studied the correlations between growth and climate change using the observational system in Africa, with cross sectional of 34 countries using range of data from 1961 to 2009. 


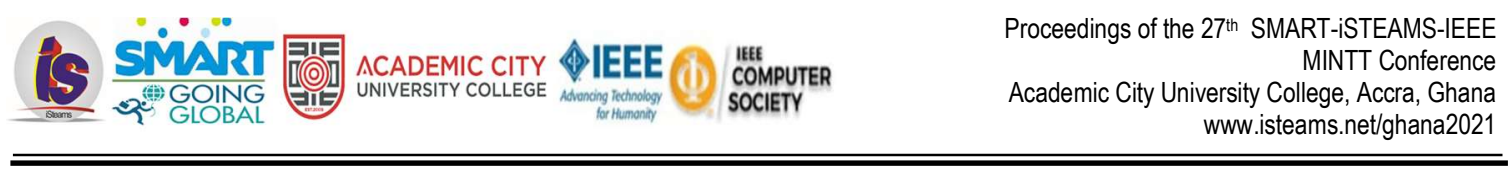

They discovered inverse shocks of change in climate on growth related of Africa. (Shoaib et al, 2020) examine the impression of change on climate to the economic improvement of Pakistan range from 1973 to 2010; they chose temperature to represent climate as a variable for analysis and established that temperature has an unfavorable relationship with growth. Ali, S. (2012), utilizing a co-integration analysis for sequence of discrete data of Ethiopia, found adverse impact of rainfall variations on growth. He particularly realized increase or decrease in droughts (dryness) have a long-term impact on growth. Zhao et al. (2017) investigate the influence of economic development on $\mathrm{CO} 2$ emissions and revealed that the intensive use of energy by the industrial sector has the potential to decouple economic growth in China. (Ha J. et al, 2018) examined the causative kinship (granger) linking climate change (Energy) and growth (economic growth) using ridge analysis with annual time sequence data between 1953 - 2013 revealed that, in short-run economic outgrowth granger causes by energy, while in the long-run it has bidirectional relation, equally using error corrections model results views bidirectional relation between energy and development in alike short and long period (Shiu A \& Lam P 2004; Zou \& Chau 2006; Chen S. et al, 2007; Yuan J. et al, 2007).

\section{RELATED REVIEW}

At the latest, Change in climate with connections amid of $\mathrm{CO} 2$ and growth bear acknowledged the frequent regards by scholars. (Shoaib et al, 2020; Mohsin M. et al, 2019; Awais M. et al, 2018; Lahiani, 2018; Marques C.A, et al 2018; Boamah et al, 2017; Bildirici M. \& Ersin 0,2017; Saboori et al, 2017; Alagidede P et al, 2015; Lanzafame, 2012; Brown et al, 2010; Jones and Olken, 2010) Awais M. et al (2018) Studies the nature of change in climate and acclimatization planning besides they viewed that, drastically change in climate affects the resources output particularly agriculture in Pakistan (land) through degradation changes, sublimation increase, carbon dioxide emission increases and excess requirements of water by plants similarly they see the frequentness in higher climate activities such as flooding, hotness, dryness, tropical windstorm and so on are inversely effect increasingly on crops output. In a related research of the same Pakistan, Mohsin M. et al, (2019) search on other economic subdivision (transport) which is assumed to consumed $23 \%$ of $\mathrm{CO} 2$ and 25 of energy globally, and examined the associated consequences of growth of economy, energy, increases in population, carbon emission, subject to transportation on ecological decay using econometrics method for empirical investigation justification.

The result views an unconditional relationship with energy and $\mathrm{CO} 2$, economic growth and consumption of energy. Alagidede P et al (2015) using panel of developing economies to extract the influence of change in climate on economic progress specifically on Africa (Sub-sahara) and concluded that, per capita (GDP) and temperature are fundamentally nonlinear. Relatively, Brown et al 2010 focuses on electricity climate volatility in sub-sahara (Africa) which has direct impact on rainfall reduction according to their finding, a higher inverse relationship with economic progress and prompt to the cutback in the income of household, agrarian output as well as the growth of economy. Equally in a similar view, Jones and Olken (2010) studies farming business and small manufacturing economies and proved that temperature undermine the effort on cross border trade. In the same region, Lanzafame (2012) with data 1962 - 2000 of more than 35 economies examined the influence of precipitation on economic growth and weather and growth using ARDL pattern he identified the short and longperiod connection linking weather and growth similarly recognize the slight impact of moisture on growth. 


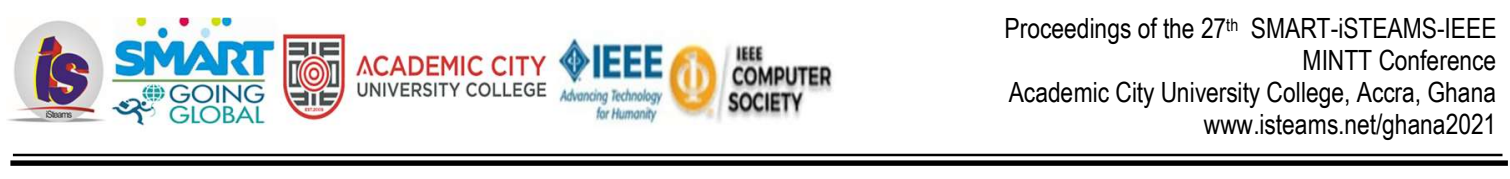

Shoaib et al, 2020 used panel data for developed and developing economies to examine the causal relation between Carbon Emission (CO2) and economic development and findings shows unidirectional flows in the developing countries and multidirectional in the developed nations at 1999 to 2013 time frames. Lahiani (2018) using 1/4 of 12 months for the period of 1960-2014 inquired the connections between Co2 emission and growth, the result shows unidirectional flow from growth to Co2 couple of long and short period. Boamah et al (2017) determined the long-period connection between economic growth and CO2. Bildirici \& Ersin (2017) used long range American data to examine the correlation between growth and CO2 using STARDL model at both short and long period and revealed the flows of long and short term asymmetric relationship in the series. (Marques et al, 2018) conducted an empirical analysis to establish the correlation that exist from economic development and carbon emission 1965 to 2016 using EKC and DI comes up with pact that, there's causal relation from growth to $\mathrm{CO} 2$ emission accordingly with ecological abasement

Mardani et al. (2018) conducted a general overlook on the connection between growth of economy to emissions on $\mathrm{CO} 2$ using the PRISMA analysis approach that covered studies of 175 articles by 55 authors published between 1995 and 2017. Their findings showed that, as a result of the unidirectional influence that prevail between $\mathrm{CO} 2$ and growth on economy, policy makers attempted to reduce emissions by changing economic growth strategies. Saboori B et al (2017) combined three oil producing economies and examined the causal relationship that flow on emission, growth and oil exhaustion by testing empirical data of S/Korea, China republic and Japan through the term 1980 to 2013 and comes up with relationship at long term on Oil usage and growth similarly proved that oil caused growth for both Japan and China, however, emission only caused by oil in S/Korea. Furthermore, proved that growth has direct impact on oil in S/Korea and China while inverse impact on Japan. Dell M. et al (2012) Using previous records studied the influence of temperature (climate) on economic output, this study subjected to multiple procedures; thus micro manifestation and extended reviews which proved the multiplicity impact of temperature on growth by accessing the influence of weather and rain of some selected countries between 1950 to 2003 with GDP as a dependent variable, the result shows the excessive inverse impact on temperature to the growth of the economy, equally, Burke (2015) shows that temperature has an indirect influence on output on all economies. Sequeira et al (2018) evaluate the effectuate nature of on universe of climate and growth using mathematical evaluation and viewed that increase in weather (temperature) and proved that does not affect individual output on population globally, thereby revealing how positively increase in rain and negatively increase in temperature in destitute economies

Empirical studies that examining the link between the variables have mostly used the linear framework. However, in the presence of nonlinearity in the data, these methods are subjected to misspecification error and can therefore lead to invalid inferences. Based on the above, this research subscribe to the literature through employing the nonlinear Granger tests for Nigeria to find the reliable causal direction between economic growths and climate change with $\mathrm{CO} 2$ emissions and temperature as a proxy. Presently, we do not across any study with regards to Nigeria that explores the relationship among the variables using nonparametric methods. For this reason on the leading gold of this inquiry to swell the gap in the previous studies. The remainder of the essay scaled as ab ide: Part 1 introduction and a review of literature, Part 2 describe the applied methodologies. Part 3 explained the results on empirical and data of the study and the part 4 give conclusions of the paper. 


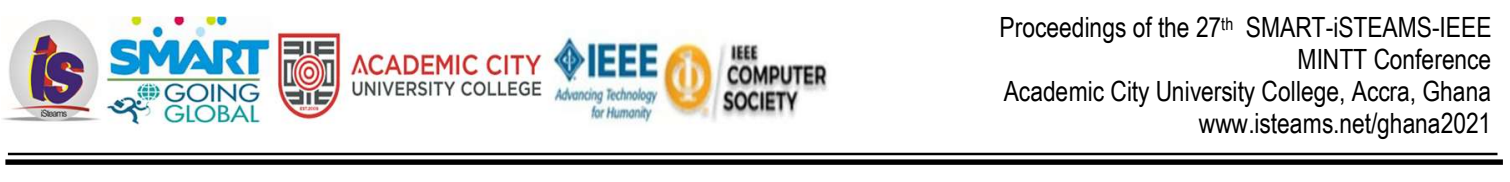

\section{METHODOLOGY}

This research work examines the correlations among output growth, local temperature level, and emissions on CO2. We designate real gross domestic product as $y_{t}$, the local level of temperature as $x_{t}$ and Carbon Dioxide as $\mathrm{z}_{\mathrm{t}}$. The model is expressed by the following equation:

$$
y_{t}=y_{0}+y_{1} x_{t}+\gamma_{2} z_{t}+\varepsilon_{t}
$$

To capture the Granger causality on nonlinear, addendum to the test of linear Granger (1969), the researchers take on two additional tests of Hiemstra \& Jones (HJ 1994) and Diks \& Panchenko (DP 2006). The linear (parametric) Granger causality test may inaccurately unfold the bearing of influence owing to being nonlinear existence relinquished. Through the two above-mentioned nonparametric methods, we can successfully deal with such limitations by considering the potential nonlinearities in the causal linkages. (HJ, 1994) developed a distribution-free technique in line with the test developed by Baek and Brock (1992) for conditionally independence. This is to clarify the HJ test; the researchers, firstly need to bring into account multi-variance series analysis: $\left(X_{t}\right)$ and $\left(Y_{t}\right)$. The test for Granger causality requires detecting manifestation opposed to null hypothesis of $\mathrm{H}_{0}:\left(\mathrm{X}_{t}\right)$ does not Granger cause $\left(\mathrm{Y}_{t}\right)$.

When no limitations are applied to the model, for example, the assumption of a restricted order of the process, conditioning on the boundless past is not possible in a nonparametric approach (Diks and Panchenko, 2006). Hence, $\left\{X_{t}\right\}$ and $\left\{Y_{t}\right\}$ are respectively specified as lagged vectors of $X_{t}^{l x}=$ $x_{t-l x+1, \ldots \ldots \ldots, X_{t}}$ and $Y_{t}^{\mathrm{l} y}=y_{t-l y+1, \ldots \ldots \ldots, Y_{t}}$ with finite lag lengths equal to $\mathrm{I}_{\mathrm{x}}$ and $\mathrm{l}_{\mathrm{y}}$. For finite lag lengths, the following tests is defined for conditional independence

$$
\left(Y_{t+1} \mid X_{t}^{\mathrm{l} x}, Y_{t}^{\mathrm{l} y}\right) \sim\left(Y_{t+1} \mid Y_{t}^{\mathrm{ly}}\right)
$$

Let $V_{t}=Y_{t}+1, W_{t}=\left(X_{t}^{\mathrm{lx}}, Y_{t}^{\mathrm{lx}}, V_{t}\right)$ that is an $\left(\mathrm{l}_{\mathrm{x}}+\mathrm{l}_{\mathrm{y}}+1\right)$ dimensional vector with an invariant distribution. The null hypothesis, determined as the proportions of joint distributions, displays the distribution conditional to $V_{t}$ specified that $(X, Y)=(x, y)$ is similar to which $V$ given $Y=y$ simply.

$$
\frac{f X, Y, V(x, y, v)}{f Y(y)}=\frac{f X, Y(x, y)}{f Y(y)} \cdot \frac{f Y, V(y, v)}{f Y(y)}
$$

In the above equation, we resemble

$f X, Y, V(x, y \mid v)-f X, Y(x \mid y)-f y, V(y . v \mid v)$ which demonstrates that $X$ and $V$ are autonomous hypothetically on $Y=y$, for any constant value of $y$. The difference between the left hand side of the equation and right-sides of the Equation (3) can be acquired through computing the ratios of correlation integrals expressed in the following:

$$
\frac{C X, Y, V(x, y, v)}{C Y(y)}=\frac{C X, Y(x, y)}{C Y(y)} \cdot \frac{C Y, V(y, v)}{C Y(y)}
$$


To recognize the bearing of the Granger causality, we should calculate the sample variants of the correlation value in Equation (4) and then we should move through to the testing of the statistical equality of the left and right-side of the ratios.

$$
C_{W, n}(\varepsilon)=\frac{2}{C_{Y}(y)} \sum \sum \mathrm{l}_{i, j}^{W}
$$

y Where, $\mathrm{l}_{i, j}^{W}$ is equal to $I\left(/ / W_{i}-W_{j} / / \leq \varepsilon\right)$. Diks and Panchenko $(2005,2006)$ in their reasoning identified that the null conjuncture under the HJ test is miss-specified; therefore it has inclination to over-decline the null. Consequently, (DP, 2006) multiplied Equation (3) with a positive significance function, $Q(x, y, v)$, so as the null of $H J$ test is adjusted. By allowing $Q(x, y, v)=f_{y}^{2}$, the simplified $Q$ can be displayed as:

$$
Q=E\left[f_{X, Y, V}(X, Y, V) f_{Y}(Y)-f_{X, Y}(X, Y) f_{Y, V}(Y, V)\right]
$$

Having specified Equation (6), under the D-P modus, the test statistic can be formularized as the following equation:

$$
\mathrm{T}_{\mathrm{n}}\left(\epsilon_{\mathrm{n}}\right)=\frac{n-1}{n(n-1)} \times \sum_{i=1}^{n}\left(\hat{f}^{\wedge}, \mathrm{Y}, \mathrm{V}\left(X_{i}, Y_{i}, V_{i}\right) \hat{f}_{Y,}^{\wedge}\left(Y_{i}\right)-f \mathrm{X}, \mathrm{Y}\left(\mathrm{X}_{\mathrm{i}}, Y_{\mathrm{i}}\right) \dot{f} \mathrm{Y}, \mathrm{V}\left(\mathrm{Y}_{\mathrm{i}}, V_{\mathrm{i}}\right)\right)
$$

Here, $\epsilon_{\mathrm{n}}$ denotes a bandwidth that is relying upon the sample size $\mathrm{n}$. An adequately high optimal frequency range may be selected to generate steady and effective estimates. Empirical claim following Diks and Panchenko (2006) usually restrict the bandwidth selection within the bounds $[0.5,1.5]$.

\section{EMPIRICAL FINDINGS AND DATA COLLECTIONS}

We collected the available annual data of real GDP per capita, local level of temperature and CO2 emissions covering the period from 1960 to 2015 for Nigeria. Our data sets are tabulated from different sources. Real output per Capita data was secured from the world Bank data, also Temperature' data from the Climate Change Knowledge Portal database and the data on $\mathrm{CO} 2$ emissions has been gathered from the Global Carbon Atlas database. To adjust dimensional discrepancy between the sequences, we transformed all variables on the logarithmic form. Following the path of Shahbaz et al. (2018), the data are then reformed into quarterly sequence using a quadratic match-sum method. Which enable us to correct the seasonal variation of the data (Shahbaz et al., 2018).

Through the application of a battery of unit root tests, our initial examination regarding the level of integration of each series illustrated that there was unit root on the variables and are non-stationary at the log levels. Given that both linear and nonlinear methodologies necessitate mean reverting properties (stationary), hence all series have been converted into the first-difference form (i.e., growth rates). Empirical analysis arises from the summary statistics of log difference of each series indicated in Table 1 . The results show that both economic and emissions growth are right skewed, while the growth of temperature is left skewered. Moreover, all variables have fat tails, which lead to the non-normal distribution. This fact is supported by the bounce of null as regards to normality of the Jarque-Bera statistic at 1 percent significance level. 


\section{Board1. Summary Statistics}

\begin{tabular}{llll}
\hline Statistics & GR & TM & CO2 \\
\hline Mean & 0.325 & 3.294 & 1.902 \\
Median & 0.385 & 3.295 & 0.928 \\
Maximum & 15.484 & 3.336 & 38.886 \\
Minimum & -8.452 & 3.238 & -24.092 \\
Std. Dev. & 2.472 & 0.019 & 7.772 \\
Skewness & 0.639 & -0.201 & 0.367 \\
Kurtosis & 11.201 & 3.732 & 10.352 \\
Jarque-Bera & $495.521^{\star \star *}$ & $50.788^{\star * *}$ & $170.326^{\star \star *}$ \\
\hline
\end{tabular}

$\mathrm{GR}, \mathrm{TM}$ and $\mathrm{CO} 2$ are abbreviating the growth rate, temperature level and growth of $\mathrm{CO} 2$ emission respectively. ${ }^{* * *}$, denote significance at $1 \%$.

However, for a reason of comparability, we also employ the standard linear Granger causality test. This method is built on the basis of the linear vector autoregressive model of order $p$ (VAR (p)). We select the desirable lags length of $p=1$ for the VAR $(p)$ model adopting the parsimonious Schwarz Information Criterion (SIC).

Board2. Granger causality test (Standard linear)

\begin{tabular}{ccccc}
\hline \multicolumn{2}{c}{ Null- H } & & F-S & p-V \\
\hline TM & $\mathrm{D} \rightarrow$ & GR & 4.21 & 0.24 \\
GR & $\mathrm{D} \rightarrow$ & TM & 2.25 & 0.16 \\
CO2 & $\mathrm{D} \rightarrow$ & GR & 5.28 & 0.19 \\
GR & $\mathrm{D} \rightarrow$ & CO2 & 1.29 & 0.39 \\
\hline
\end{tabular}

Notice: Peculiarity disclosed that F-statistics are realized using a pretty much LVAR model of I(1). Null-P mean Hull Hypothesis, F-S mean F-Statistic and P-V mean Probability value, LVAR mean linear vector autoregressive $(\mathrm{D} \rightarrow$ ) mean does not granger cause

Board 2 summarizes the outcome of the standard linear test. Just as can be seen, we could not find any evidence of a casual linkage for each pair of variables. The null hypothesis of non-causality for each pair of variables cannot be repudiated at any stipulated level of consequence. The above finding must be interpreted with caution, as the standard linear Granger test is biased with the appearance of structural breaks and nonlinearity. Many studies have shown that the parametric methods do not provide $\rightarrow$ consistent and reliable results, as they suffer from the instability that arises from the existence of structural changes (Saliminezhad and Lisaniler, 2018). Hence, we turn to the next part of this study that provides an evaluation of the linear framework using the independence test (BDS test) of Brock et al. (1996). Board 3 present the tested results of the BDS test under the null of the i.i.d. residuals of the VAR (1) model for each pair of series. It is clearly observable that the null of linear dependency is rejected across all embedding (M) dimensions. This supports the beinghood of a nonlinear connection among the variables. Thereby, we can ascertain that, the causal reasoning subject on the direct Granger test are not plausible as they are subjected to invalidity in the existence of nonlinearity. 
Board3. Brock et al. (1996) Independent test (BDS test).

\begin{tabular}{|c|c|c|c|c|c|}
\hline & \multicolumn{5}{|c|}{ M } \\
\hline & 2 & 3 & 4 & 5 & 6 \\
\hline $\operatorname{VAR}(1):[T M, G R]:$ & 0.0000 & 0.0000 & 0.0000 & 0.0001 & 0.0001 \\
\hline $\operatorname{VAR}(1):[\mathrm{CO} 2, \mathrm{GR}]:$ & 0.0000 & 0.0000 & 0.0000 & 0.0001 & 0.0001 \\
\hline
\end{tabular}

Notice: $m$ stand for the number of (fixed) dimensions which drive-ins the time series within m-dimensional vectors, by taking each $(\mathrm{m})$ sequential points in the series. Value in cell symbolizes the $p$-value of the BDS z-statistic with the zero of i.i.d. residuals.

Due to the presence of nonlinearity in the nexus of the variables, we now turn to the examination of the nonlinear causation between the pair of variables. In this vein, we apply the nonlinear test of $(\mathrm{H}-\mathrm{J}, 1994$; $D-P, 2006)$. In performing this stage, we apply the strapping series of the embedding measurement (N) of 2, 3 and 4 against the applied lag order of one in the model. Refers to Diks \& Panchenko, (2006) for more, both results are indicated in board 4 and 5, respectively. As indicated in the board 4 below, there is manifest for the rejection of the null hypothesis of non-causal relation from economic growth to temperature level when the embedding dimension is 2 and 3 . However, we could not find any manifest of a causal relationship from temperature to economic growth.

Board4: Nonlinear Granger causality test, Hiemstra-Jones (1994).

\begin{tabular}{|c|c|c|c|c|c|c|}
\hline \multirow[b]{3}{*}{$\mathrm{TM} \rightarrow \mathrm{GR}$} & \multicolumn{2}{|l|}{$m=2$} & \multicolumn{2}{|l|}{$m=3$} & \multicolumn{2}{|l|}{$m=4$} \\
\hline & T-S & $\mathrm{P}-\mathrm{V}$ & T-S & P-V & T-S & P-V \\
\hline & 1.07 & 0.11 & $\overline{0}-04$ & 0.42 & 0.27 & 0.39 \\
\hline $\mathrm{GR} \rightarrow \mathrm{TM}$ & $\begin{array}{l}- \\
2.36\end{array}$ & 0.01 & $\overline{1.38}$ & 0.02 & 0.72 & 0.21 \\
\hline $\mathrm{CO} 2 \rightarrow \mathrm{GR}$ & $\overline{-}-69$ & 0.24 & $\begin{array}{l}- \\
1.10\end{array}$ & 0.13 & $-\overline{0}$ & 0.41 \\
\hline $\mathrm{GR} \rightarrow \mathrm{CO} 2$ & $-\overline{0.78}$ & 0.22 & $-\overline{1.20}$ & 0.11 & 0.72 & 0.23 \\
\hline
\end{tabular}

Note: $M$ symbolizes the number of (embedded) dimensions. Results are presented with the bandwidth $\left(\epsilon_{n}\right)$ adjustment of 0.65 . T-S means Test statistic, P-V mean Probability value

This inferred that, there is a unidentate causality from economic growth to the temperature level. For the other pair of series (economic growth and $\mathrm{CO} 2$ emissions), the null of non-causality between the variables cannot be rejected at any conventional significance level. Surprisingly, a neutral effect for the CO2-growth nexus has been shown in Nigeria through the HJ test. 
Board 5: Nonlinear Granger causality test Diks and Panchenko (2006).

\begin{tabular}{lllllll} 
& \multicolumn{1}{c}{$\mathrm{m}=2$} & \multicolumn{3}{c}{$\mathrm{m}=3$} & $\mathrm{~m}=4$ & \\
\cline { 2 - 7 } $\mathrm{TM} \rightarrow \mathrm{GR}$ & $\mathrm{T}-\mathrm{S}$ & $\mathrm{p}-\mathrm{v}$ & $\mathrm{T}-\mathrm{S}$ & $\mathrm{p}-\mathrm{v}$ & $\mathrm{T}-\mathrm{S}$ & $\mathrm{p}-\mathrm{v}$ \\
\cline { 2 - 8 } $\mathrm{GR} \rightarrow \mathrm{TM}$ & 1.91 & 0.02 & 1.11 & 0.09 & 0.38 & 0.34 \\
$\mathrm{CO} 2 \rightarrow \mathrm{GR}$ & - & 0.08 & 1.29 & 0.07 & 0.75 & 0.23 \\
& 1.32 & & & & & \\
$\mathrm{GR} \rightarrow \mathrm{CO} 2$ & 0.34 & 0.42 & 0.95 & 0.16 & 1.65 & 0.04 \\
\hline
\end{tabular}

Note: $m$ symbolizes the number of (embedded) dimensions. Results are presented with the bandwidth $\left(\epsilon_{n}\right)$ adjustment of 0.65 . T-S means Test statistic, P-V mean Probability value

The results of board 4 are suffering from the problem of over-rejection, as identified by Diks and Panchenko (2006). However, we adjust for this problem through the application of the nonlinear test of DP, which is free from estimation bias. The results in board 5 show the different inferences regarding the causal flow among the variables. We detect the appearance of a nonlinear causality flowing from economic development (growth) to $\mathrm{CO} 2$ emissions under the case that the embedding dimension is 2 and 3 . This result contradicts the findings of Rafindadi (2016), who detected the existence of adverse effect between economic development and $\mathrm{CO} 2$ emissions in Nigeria through the linear Granger causality test. For the other variables, evidence of a bi-directional causality has been found. We reject the null of non-causality between the temperature level and economic growth under the embedding dimension $(\mathrm{m})$ of 2,3 .

\section{CONCLUSION}

Significant evidence has been found showing the negative impacts of climate change, such as increase in temperature, rainfall, sea level, desertification, flooding and drought. This evidence shows that climate change is indeed a reality and also has the potential to impose particular effects on economic activities, and Nigeria is no exception to this phenomenon. The findings of this study indicate that there are different inferences regarding the causal flows among $\mathrm{CO} 2$ emissions, temperature and economic growth using the nonlinear Granger causality test developed by Diks and Panchenko in 2006. We provide evidence of a nonlinear causality running from economic growth to $\mathrm{CO} 2$ emissions, while for the other couple of variables, evidence of a bi-directional causality has been found. It should be noted that the use of the linear Granger causality test could not discover any causal relationship between any pair of variables; however, this result is not reliable when nonlinearity exists in the data.

In summary, our findings provide valuable data for policy makers who are seeking greater insights on the relationship between the series. This highlights the prominance on the modeling of nonlinear symbioses between the variables through nonparametric methodology. 


\section{REFERENCES}

1. Abidoye, B. O., Odusola, A. F. (2015). Climate change and economic growth in Africa: an econometric analysis. Journal of African Economies, 24(2), 277-301.

2. Akpodiogaga-a, P., Odjugo, O. (2010). General overview of climate change impacts in Nigeria.

3. Journal of Human Ecology, 29(1), 47-55.

4. Alagidede P, Adu G and Frimpong P. B (2018) The effect of climate change on economic growth: evidence from Sub-Saharan Africa Environ Econ Policy Stud (2016) 18:417-436- Society for Environmental Economics and Policy Studies and Springer Japan 2015 - DOI 10.1007/s10018-0150116-3

5. Ali, S. (2012). "Climate Change and Economic Growth in a Rain-fed Economy: How Much

6. Does Rainfall Variability Cost Ethiopia?" Available at SSRN 2018233.

7. Awais M, Wajid A, Saleem M. F, Nasim W, Ahmad A, Raza M. S, Bashir M.U, Mubeen M, Hammad H.M, Habibur-Rahman M, Saeed U, Arshad M. N, \& Hussain J (2018) Potential impacts of climate change and adaptation strategies for sunflower in Pakistan Environmental Science and Pollution Research (2018) 25:13719-13730 Springer-Verlag GmbH Germany, part of Springer Nature 2018 https://doi.org/10.1007/s11356-018-1587-0

8. Ayuba HK, Maryah UM, Gwary DM (2007). Climate change impact on plant species

9. composition in six semi-arid rangelands of Northern Nigeria. Nigerian Geographical Journal 5(1): 35-42.

10. Baek, E., \& Brock, W. (1992). A general test for nonlinear Granger causality: Bivariate model. lowa State University and University of Wisconsin at Madison Working Paper

11. Beyioku J. (2016) Climate change in Nigeria: A brief review of causes, effects and solution https://fmic.gov.ng/climate-change-nigeria-brief-review-causes-effects-solution/

12. Bildirici M. \& Ersin O. (2017) Economic growth and CO2 emissions: an investigation with smooth transition autoregressive distributed lag models for the 1800-2014 period in the USA Environ Sci Pollut Res (2018) 25:200-219- Springer-Verlag GmbH Germany 2017, corrected publication November/2017 -DOI 10.1007/s11356-017-0244-3

13. Boamah K.B, Du J, Bediako A, Boamah A.J, Abdul-Rasheed A.A, \& Owusu S.M (2017) Carbon dioxide emission and economic growth of China-the role of international trade Environ Science Pollution Research (2017) 24:13049-13067, Springer-Verlag Berlin Heidelberg 2017 DOI 10.1007/s11356017-8955-z

14. Broock, W. A., Scheinkman, J. A., Dechert, W. D., \& LeBaron, B. (1996). A test for independence based on the correlation dimension. Econometric reviews, 15(3), 197-235.

15. Burke (2015) Global non-linear effect of temperature on economic production- Nature 527:235-239

16. Chen, J., Cheng, S., Nikic, V., Song, M., 2018. Quo vadis? Major players in global coal consumption and emissions reduction Transform. Bus. Econ. 17

17. Chen S-T, Kuo H-I, Chen C-C. The relationship between GDP and electricity consumption in 10 Asian countries. Energy Policy. 2007; 35(4):2611 \pm 21.

18. Choi E., Heshmati A., and Cho Y (2010) An Empirical Study of the Relationships between $\mathrm{CO} 2$

19. Emissions, Economic Growth and Openness, IZA Discuss Paper No. 5304.

20. Dell, M., Jones, B. F., \& Olken, B. A. (2012). Temperature shocks and economic growth: Evidence from the last half century. American Economic Journal: Macroeconomics, 4(3), 66-95.

21. Diks, C., \& Panchenko, V. (2005). A note on the Hiemstra-Jones test for Granger noncausality. Studies in nonlinear dynamics \& econometrics, 9(2). 
22. Diks, C., Panchenko, V. (2006). A new statistic and practical guidelines for nonparametric Granger causality testing, Journal of Economic Dynamics and Control, 30(9-10), 1647-1669

23. Fankhauser, S., and R. SJ Tol. 2005. "On Climate Change and Economic Growth."

24. Friedl B. and M. Getzner (2003), Determinants of CO2 emissions in a small open economy,

25. Ecological Economics 45, 133-148.

26. Granger, C. J. (2006) Investigating Causal Relationships by Econometrics Models and Cross Spectral Methods." Econometrica, Vol. 37, 1969: 425-435.

27. Ha J, Tan P-P, Goh K-L (2018) Linear and nonlinear causal relationship between energy consumption and economic growth in China: New evidence based on wavelet analysis. PLoS ONE 13 (5): e0197785. https://doi.org/10.1371/journal. pone.0197785

28. Hiemstra, C., Jones, J.D. (1994). Testing for linear and nonlinear Granger causality in stockprice volume relation. Journal of Finance, 49, 1639-1664.

29. Jagtap S (2007). Managing vulnerability to extreme weather and climate events: Implications for agriculture and food security in Africa. Proceedings of the International Conference on Climate Change and Economic Sustainability held at Nnamdi Azikiwe University, Enugu, Nigeria. 12-14 June 2007.

30. Jones B and Olken B (2010) Climate shocks and exports, NBER Working Paper No. 157

31. Lahiani $A$ (2018) Revisiting the growth-carbon dioxide emissions nexus in Pakistan Environmental Science and Pollution Research (2018) 25:35637-35645 Springer-Verlag GmbH Germany, part of Springer Nature 2018 https://doi.org/10.1007/s11356-018-3524-7

32. Lanzafame M (2012) Temparature, rainfall and economic growth in Africa- Empirical Economic. doi:10.1007/s00181-012-0664-3

33. Liu, C., Xiong, K., Wang, W., Zhang, T., Tang, J., 2016. An empirical research on the determinants of Chinese college students' carbon label cognition and interpersonal communication willingness. Chin. J. Popul. Resour. Environ. 14, 309-318.

34. Mardani A, Streimikiene D, Cavallaro F, Loganathan N and Khoshnoudi M (2018) Carbon dioxide (CO2) emissions and economic growth: A systematic review of two decades of research from 1995 to 2017 Science of the Total Environment journal homepage: doi.org/10.1016/j.scitotenv.2018.08.229 0048-9697/C 2018 Elsevier B.V. All rights reserved.

35. Marques C.A, Fuinhas J.A. \& Leal P. A. (2018) The impact of economic growth on CO2 emissions in Australia: the environmental Kuznets curve and the decoupling index Environmental Science and Pollution Research (2018) 25:27283-27296 - Springer-Verlag GmbH Germany, part of Springer Nature 2018 https://doi.org/10.1007/s11356-018-2768-6

36. McMicheal A. J, Butler C.D and Dixon J (2015) Climate change, food systems and population health risks in their eco-social context. Public Health journal homepage: $\quad$ www.elsevier.com/puhe, p u b l i c health $129(2015) 1361 \mathrm{e} 1368$

37. Mohsin M, Abbas Q, Zhang J, Ikram M \& lqbal N (2019) Integrated effect of energy consumption, economic development, and population growth on $\mathrm{CO} 2$ based environmental degradation: a case of transport sector Environmental Science and Pollution Research (2019) 26:32824-32835 SpringerVerlag GmbH Germany, part of Springer Nature 2019 https://doi.org/10.1007/s11356-019-06372-8

38. Moomaw W.R. and G.C. Unruh (1997), Are environmental Kuznets curves misleading us? The case of $\mathrm{CO} 2$ emissions, Environment and Development Economics 2, 451-463.

39. Nigerian Environmental Study/Action Team (NEST) (2003). Climate Change in Nigeria- A Communication Guide for Reporters and Educators, Ibadan: NEST pp. 5-16. 
40. Nwafor JC (2007). Global climate change: The driver of multiple causes of flood intensity in SubSaharan Africa. Paper presented at the International Conference on Climate Change and Economic Sustainability held at Nnamdi Azikiwe University, Enugu, Nigeria, 12-14 June 2007.

41. Rafindadi, A. A. (2016). Does the need for economic growth influence energy consumption and CO2 emissions in Nigeria? Evidence from the innovation accounting test. Renewable and Sustainable Energy Reviews, 62, 1209-1225.

42. Ruth D. (2017) Nigeria: Impact of Climate Change on Health in Nigeria This Day newspaper (Lagos) https://allafrica.com/stories/201710030155.html 23/11/2018.

43. Saboori B et al (2017) The nexus of oil consumption, CO2 emissions and economic growth in China, Japan and South Korea Environ Sci Pollut Res (2017) 24:7436-7455 Springer-Verlag Berlin Heidelberg 2017 DOI 10.1007/s11356-017-8428-4

44. Saliminezhad, A., Lisaniler, F. G. (2018). Validity of unbalanced growth theory and sectoral

45. investment priorities in Indonesia: Application of feature ranking methods. The Journal of International Trade Economic Development, 27(5), 521-540.

46. Sequeira T.et al (2018) Climate change and economic growth: a heterogeneous panel data approach - Environmental Science and Pollution Research, Springer-Verlag GmbH Germany, part of Springer Nature $2018 \mathrm{https}: / / \mathrm{doi} .0 \mathrm{rg} / 10.1007 / \mathrm{s} 11356-018-2305-7$

47. Shahbaz, M., Zakaria, M., Shahzad, S. J. H., Mahalik, M. K. (2018). The energy consumption and economic growth nexus in top ten energy-consuming countries: Fresh evidence from using the quantile-on-quantile approach. Energy Economics, 71, 282-301.

48. Shiu A,\& Lam P-L(2004) Electricity consumption and economic growth in China. Energy policy- 32 (1)

49. Shoaib M. H, Rafique M.Z, Nadeem A.M \& Huang S (2020) Impact of financial development on CO2 emissions: A comparative analysis of developing countries (D8) and developed countries (G8) Environmental Science and Pollution Research Springer-Verlag GmbH Germany, part of Springer Nature 2020 https://doi.org/10.1007/s11356-019-06680-z

50. Sulaiman, C. (2014). The causality between energy consumption, CO2 emissions and economic growth in Nigeria: An application of Toda and Yamamoto Procedure. Advances in Natural Applied Sciences, 8(1), 75-81.

51. Wade, K., Jennings, M. (2015). The impact of climate change on the global economy. Schroders Talking Point.

52. Wang S. L, Ball E, Nehring R, Williams R, and Chau T (2018) Impacts of Climate Change and

53. Extreme Weather on U.S. Agricultural Productivity: Evidence and projection. In Agricultural

54. Productivity and Producer Behavior. University of Chicago Press

55. Wang, X., Wu, L., 2017. Determinants of workers' attitude toward low-carbon technology adoption: empirical evidence from Chinese firms. Chin. J. Popul. Resour. Environ. 15, 80-86.

56. Yuan J, Zhao C, \& Yu S, Hu Z (2007) Electricity consumption and economic growth in China: cointegration and co-feature analysis. Energy Economics 2007; 29(6)

57. Zhao, X., Zhang, X., Li, N., Shao, S., Geng, Y., (2017) Decoupling economic growth from

58. carbon dioxide emissions in China: a sectoral factor decomposition analysis. J. Clean. Prod. 142, 3500-3516.

59. Zou G\& Chau K(2006). Short-and long-run effects between oil consumption and economic growth in China. Energy Policy - 2006; 34(18) 